\title{
Use of nighttime visible images to detect Japanese common squid Todarodes pacificus fishing areas and potential migration routes in the Sea of Japan
}

\author{
Hidetada Kiyofuji*, Sei-Ichi Saitoh \\ Laboratory of Marine Environment and Resource Sensing, Graduate School of Fisheries Sciences, Hokkaido University, \\ 3-1-1 Minato-Cho, Hakodate, Hokkaido 041-8611, Japan
}

\begin{abstract}
This study used Defense Meteorological Satellite Program (DMSP)/Operational Linescan System (OLS) satellite images to classify and analyze the spatial and temporal variability of nighttime fishing vessel lights in the Sea of Japan. OLS images can detect the powerful lights used to attract squid. We examined DMSP/OLS nighttime visible images from 1994 to 1999. Fishing areas of the Japanese common squid Todarodes pacificus were defined as the bright areas created by 2-level slicing methods on DMSP/OLS images. T. pacificus fishing areas were mainly found along the east coast of Korea, between Cheju and Tsushima Islands, around the Yamato Rise, along the coast of Honshu, and in northern areas of the Sea of Japan. Using image classification and separability analysis, we divided the Sea of Japan into 7 areas based on different temporal variability in squid fishing area characteristics. The classification takes the potential northern and southern squid migration patterns into account. One of the potential northern migration patterns formed along Honshu Island to the north; another appeared along the east coast of Korea, northward through Yamato Rise. Southern migration patterns were almost the reverse of northern migration patterns. These 7 classified areas also correspond to the oceanographic characteristics of the Sea of Japan, i.e. a polar front at latitude $40^{\circ} \mathrm{N}$, the inflow of the Tsushima Warm Current (TWC), and warm eddies. The use of remotelysensed data demonstrated in this study offers a powerful and innovative way in which to determine the migration and ecology of the Japanese common squid.
\end{abstract}

KEY WORDS: Defense Meteorological Satellite Program/Operational Linescan System · Nighttime visible image $\cdot$ Squid fishery $\cdot$ Fishing vessel $\cdot$ Todarodes pacificus $\cdot$ Sea of Japan · Classification

\section{INTRODUCTION}

Cephalopods are an important fisheries resource world-wide, not only as food but also because of their role in the energy and material flows within marine ecosystems (Piatkowski et al. 2001). Total cephalopod landings have increased since 1950 (FAO 2003: Total production 1950-2001: www.fao.org/fi/statist/fisoft/ fishplus.asp) and total landings in 2001 were over 3.3 million t. The total cephalopod catch of Japan in 2001 was 520982 t, i.e. about one-sixth of the total world catch. The Japanese common squid Todarodes pacificus catch constitutes approximately $56 \%$ of the total cephalopod catch in Japan, and constitutes the majority of the Japanese squid catch. The total catch of
T. pacificus in Japan has varied widely, with relatively low catches $(<200000$ t) until 1950. The lowest catch was $25000 \mathrm{t}$ in 1908 and the highest catch was 668000 $\mathrm{t}$ in 1968. There was then a gradual decrease that began in the 1970s, followed by an increase after 1986 (Fig. 1a). The lowest catch since then was in 1998, when $180749 \mathrm{t}$ were recorded; this was $40 \%$ of Japan's largest recorded catch, which was made during 1996 (Fig. 1b). It is important to determine whether fluctuations in the T. pacificus catch are due to overfishing or to environmental changes or both. Recent research (Sakurai et al. 2000) has shown that variations in oceanographic conditions, such as extension of possible spawning areas, influence both the distribution and abundance of T. pacificus. Kang et al. (2002) 

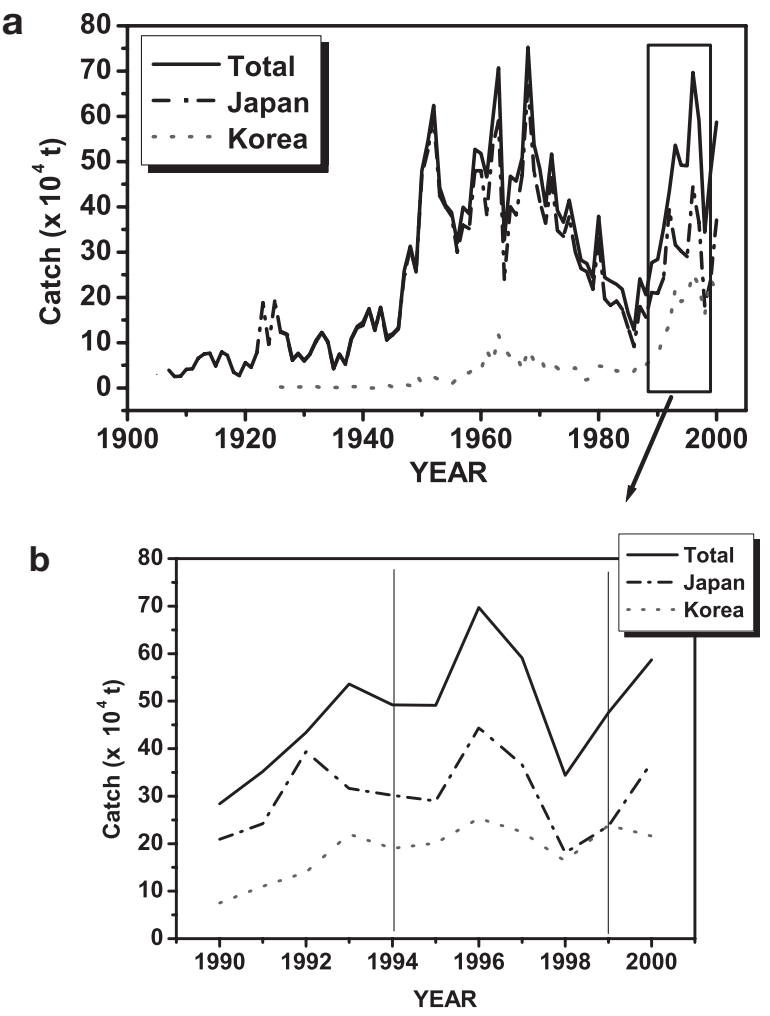

Fig. 1. Todarodes pacificus. Total catch $\left(10^{4} \mathrm{t}\right)$ of Japanese common squid from (a) 1906 to 2000 and (b) 1990 to 2000
Todarodes pacificus migrates seasonally from the southern Sea of Japan and is distributed from the East China Sea to the Maritime Province of Siberia and Sea of Okhotsk (Fig. 2). Over the last century, studies of squid in Japanese waters have focused on biology and fisheries. Numerous studies have examined spawning areas, migration routes and spawning seasons. T. pacificus spawns in 3 seasons: autumn (September-November), winter (December-February), and spring/ summer (all other months) (Murata 1989). Although recruitment occurs throughout the year, 2 spawning groups maintain the stocks in the Sea of Japan. The main spawning areas for both autumn and winter spawning groups are thought to be around the Tsushima Strait (Fig. 2). Araya (1976) the described migration and fishing areas of $T$. pacificus in the northern waters of Japan, and Hatanaka et al. (1985) and Murata $(1989,1990)$ further detailed the migration of T. pacificus also in northern waters of Japan. Kiyofuji et al. (1998) analyzed sea surface temperature (SST) imagery to identify the spawning areas of T. pacificus. The schematic map in Fig. 2 (modified from Murata 1989, 1990), combines spawning and migration data from the above studies.

The Tsushima/Korea Strait and the Tsugaru Strait connect the Sea of Japan with the East China Sea and Pacific Ocean, respectively. Soya/La Pérouse Strait

examined the relationship between zooplankton biomass and squid catch in the Sea of Japan, and concluded that increased zooplankton biomass was the main reason for increased squid catches.

The sustainable use of squid in the Sea of Japan is the primary objective of stock management. Basson et al. (1996) developed a stock assessment based on the Leslie-Delury assessment method for squid fishery in the SW Atlantic. However, they did not include information about fishing seasons and locations. Todarodes pacificus was also a target species in the 'total allowable catch' (TAC) system in 1998. T. pacificus stock management in Japan determines the $\mathrm{ABC}$ ('available biological catch') and MSY ('maximum sustainable yield'). The TAC requires information on squid distribution and migration routes in order to estimate squid standingstocks.

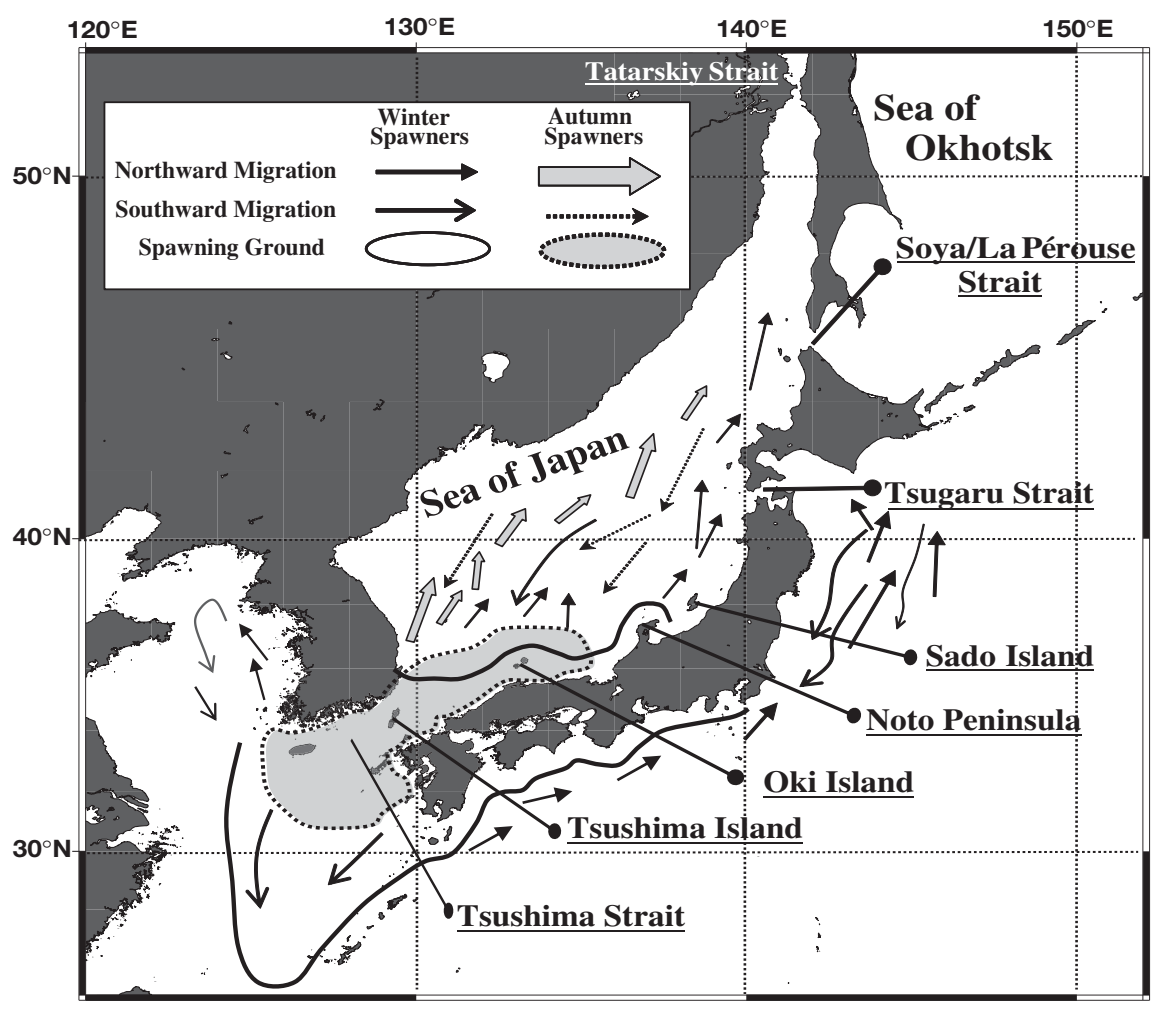

Fig. 2. Typical migration routes and spawning grounds of Todarodes pacificus (modified from Murata 1989, 1990) 


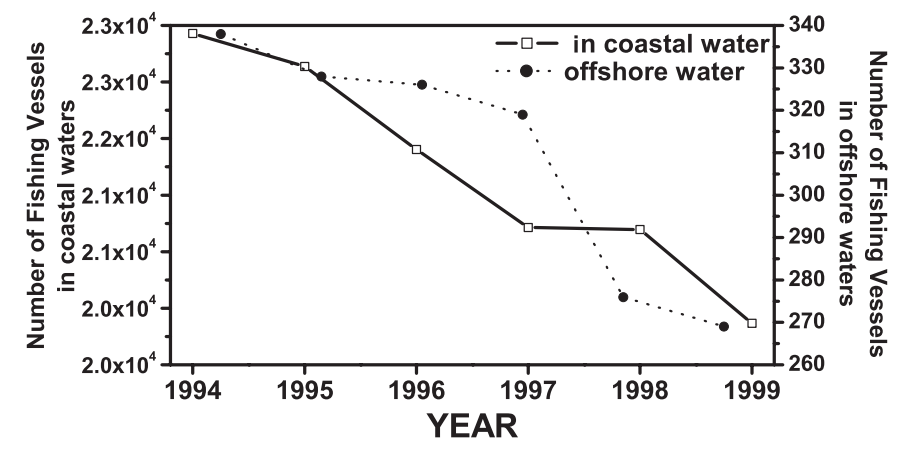

Fig. 3. Number of fishing vessels in offshore and coastal waters

and Tatarskiy Strait link the Sea of Japan to the Okhotsk Sea in the north. The major oceanographic features in the Sea of Japan are a polar front at latitude $40^{\circ} \mathrm{N}$ and the inflow of the Tsushima Warm Current (TWC) from the East China Sea (Isobe et al. 1994). The TWC forms 3 branches (Kawabe 1982), and Isobe (1999) showed that $66 \%$ of the volume transported by the TWC comes directly from the Kuroshio region in autumn. The oceanographic features of the Sea of Japan probably influence the spatial and temporal distribution of Todarodes pacificus. The locations of a number of squid fishing areas have been shown to be related to environmental phenomena such as SST detected by satellite remote-sensing (Kiyofuji et al. 2001, Waluda et al. 2001a,b). Satellite imagery is extensively used in fisheries studies to identify relationships between spatial distribution and environmental variables such as SST and ocean color. Satellite remote-sensing of SST is also a useful tool for describing large-scale oceanic phenomena and related fish distributions. Despite such studies, the large-scale distribution of T. pacificus is still difficult to determine, as surveys by research vessels are asynchronous in terms of spatial and temporal observations. New methodologies capable of deriving data on the spatial and temporal variability of $T$. pacificus distributions are required, especially given the increased need for large-scale accurate stock management.

Squid fishery is of 3 types: distant, offshore and coastal. The Japanese squid fishing vessels operate at night, using powerful lights to attract the squid. These lights can be observed on nighttime OLS (Operational Linescan System) images of the DMSP (Defense Meteorological Satellite Program). Although the number of squid fishing vessels has been decreasing from 1994 to 1999, total numbers were still above 20000 in 1999 (Fig. 3). In the images, bright-light areas around Japan are believed to be fishing vessels, especially the lights of the squid vessels targeting Todarodes pacificus. DMSP/OLS images have previously been used to identify urban areas (Imhoff et al. 1997, Owen et al. 1998).
In terms of fishery oceanography, Cho et al. (1999), Kiyofuji et al. (2001), Rodhouse et al. (2001) and Waluda et al. (2002) examined nighttime visible images to determine the spatial distribution of fishing vessels. Cho et al. (1999) and Kiyofuji et al. (2001) determined that the bright areas in the OLS images, created by 2-level slicing, were caused by light produced by the fishing vessels. Rodhouse et al. (2001) reported the frequency of light occurrences in cloud-free imagery, and associated these lights with fishing vessels. Waluda et al. (2002) analyzed a relationship between the number of lit pixels in DMSP/OLS nighttime visible images and the number of fishing vessels around the Falkland Islands' Illex argentinus fishery. Kiyofuji et al. (in press) examined the relationship between the numbers of pixels in the DMSP/OLS imagery and the numbers of fishing vessels, and demonstrated that fishing vessel numbers can be estimated from DMSP/OLS nighttime visible images in the Sea of Japan. However, there remains the problem of transforming a wide range of digital numbers in images for lighted pixels into classes differentiating the actual fishing vessels from light reflected by the sea surface.

For this study, we assumed that squid were caught in areas where fishing vessels were located. Thus, based on fishing vessel locations, we believe it is possible to estimate the spatial and temporal distribution of Japanese common squid. This study also aimed at developing a methodology for identifying the fishing fleet in DMSP/OLS visible images of the Sea of Japan, and examining seasonal variability in fishing area. We sought to provide a new perspective on the specific distribution of fishing areas, and an innovative analysis that not only examines fishing area formation, but also traces migrations throughout the Sea of Japan.

\section{MATERIALS AND METHODS}

Satellite nighttime visible images and image processing. DMSP/OLS data were provided by the NOAA National Geophysical Data Center (NGDC) Boulder, Colorado, USA. A DMSP satellite carries 6 sensors including the OLS. The OLS sensor monitors global cloud coverage day and night via 2 channels, visiblenear-infrared (VNIR) and thermal infrared (TIR), and has a swath of $3000 \mathrm{~km}$. The VNIR and TIR observe radiation from 0.5 to $0.9 \mu \mathrm{m}$, and from 10 to $13 \mu \mathrm{m}$, respectively. The VNIR band signal is intensified at night using a photomultiplier tube (PMT) for the detection of moonlit clouds. The low-light sensing capabilities of the OLS at night permit the measurement of radiance down to $10^{-9} \mathrm{~W} \mathrm{~cm}^{-2} \mathrm{sr}^{-1} \mu^{-1}$ (Elvidge et al. 1997a). However, the OLS is sensitive to scattered sun- 


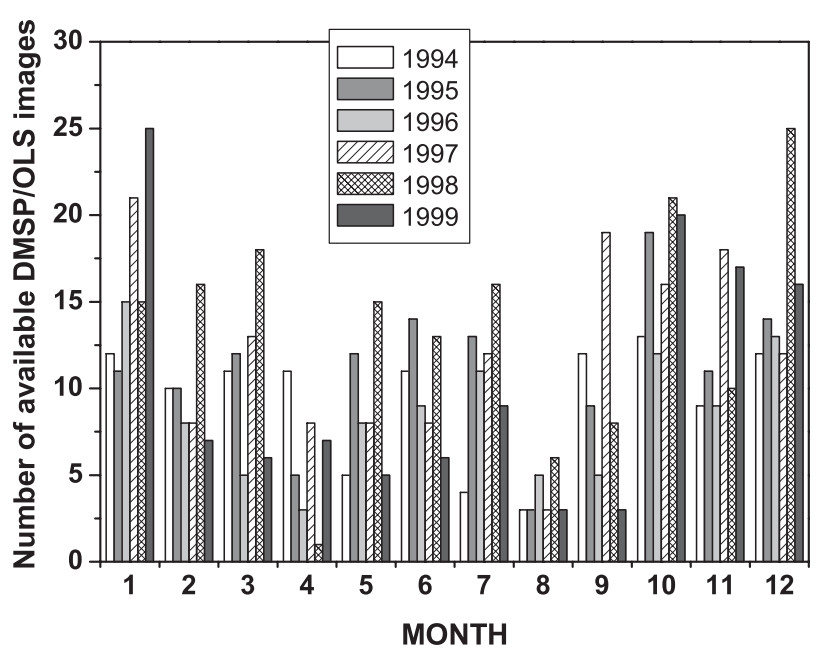

Fig. 4. Number of derived DMSP/OLS images from 1994 to 1999. (Images provided by National Geophysical Data Center [NGDC] and Agriculture, Forestry and Fisheries Research Information Center in Japan [AFF])

light, which saturates the visible band data (referred to as 'glare': Elvidge et al. 1997b). The visible band of DMSP/OLS data has a 6-bit quantization, producing digital numbers (DN) ranging from 0 to 63 (Elvidge et al. 1999). Visible digital numbers are relative rather than absolute values in $\mathrm{W} \mathrm{m}^{-2}$. The spatial resolution is $0.55 \mathrm{~km}$ during the day and $2.7 \mathrm{~km}$ at night. A search for available images on the National Geophysical Data Center (NGDC) and Agriculture, Forestry and Fisheries Research Information Center in Japan (AFF) Web sites, resulted in 786 usable nighttime images from 1994 to 1999. In each year, less than 12 images were available in April and August, with between 12 and 25 available in the other months (Fig. 4). The maximum numbers of images per month were 25 (January), 16 (February), 18 (March), 12 (April), 15 (May), 14 (June), 16 (July), 6 (August), 19 (September), 21 (October), 17 (November) and 25 (December). Higher tempera-

Fig. 5. Study area. Gray shading shows area from which data was used to examine histogram of digital number of images and for classification ture and corresponding increases in water vapor cause the paucity of usable summertime images in April and August.

Image noise, such as edges of sensor scans and high digital numbers caused by glare, was systematically removed manually, and monthly composite images in each year were then processed.

Data analysis. Annual variability in $D N$ values extracted from DMSP/OLS nighttime visible images: Once the thresholds were determined as described above, 9 areas of interest (AOI) were selected in the Sea of Japan to investigate temporal variability of squid fishing vessel formations (Fig. 5A-I). We selected 3 offshore areas (A, B, C), 2 areas along the eastern coast of Korea (D, E), and 4 areas along the coast of Japan (F, G, H, I). Each AOI was $27 \times 27 \mathrm{~km}$ and averaged digital numbers were employed as central values.

Spatial distribution of Todarodes pacificus fishing area: To extract T. pacificus fishing areas from DMSP/ OLS, we examined the histograms of the digital numbers for each month (Fig. 5). Several peaks in DN were recorded in all months (Fig. 6). Since the frequency distributions in each month differ, thresholds were determined for each month in order to extract the fishing vessels light. We applied a 2-level slicing method in order to extract the bright areas thought to be caused by the fishing fleet. This is a methodology for statistically determining an optimal threshold from the DN frequency distributions (Takagi \& Shimoda 1998).

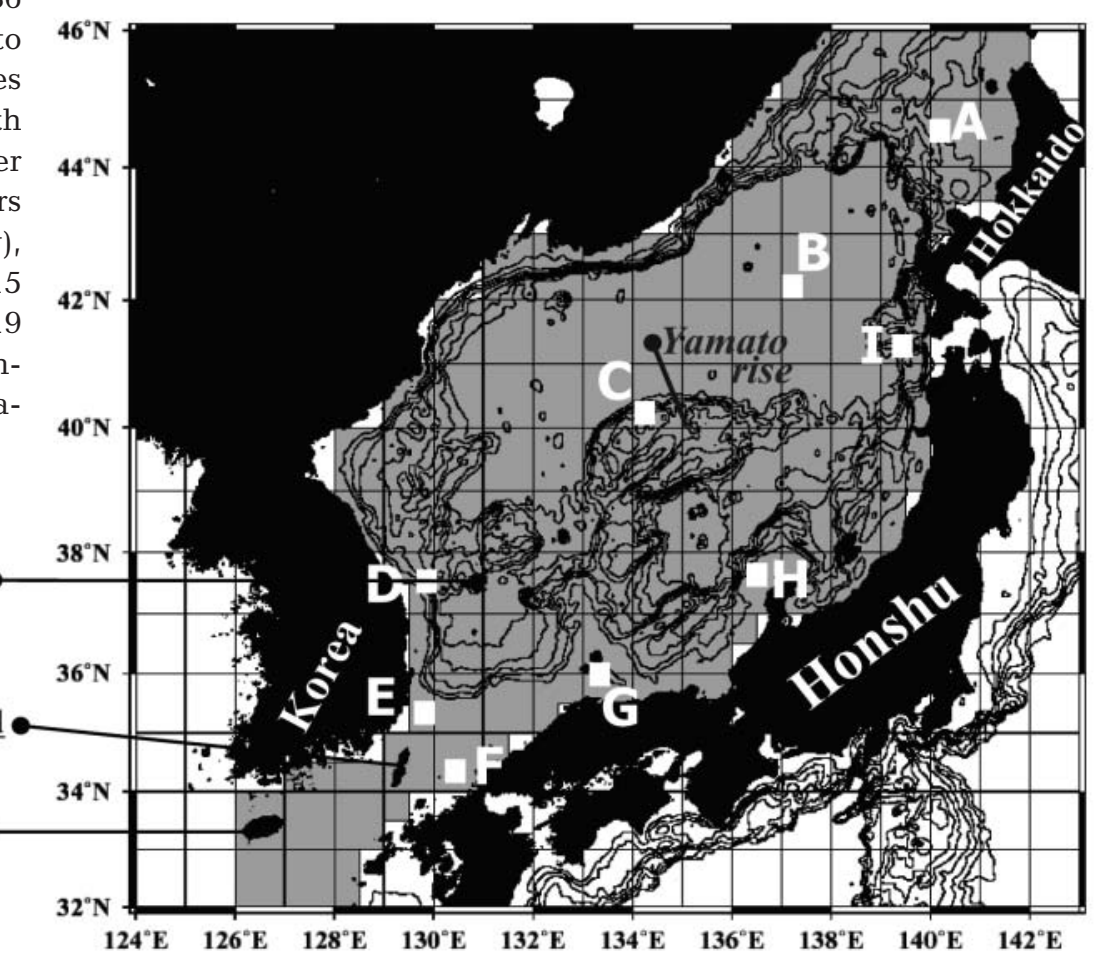




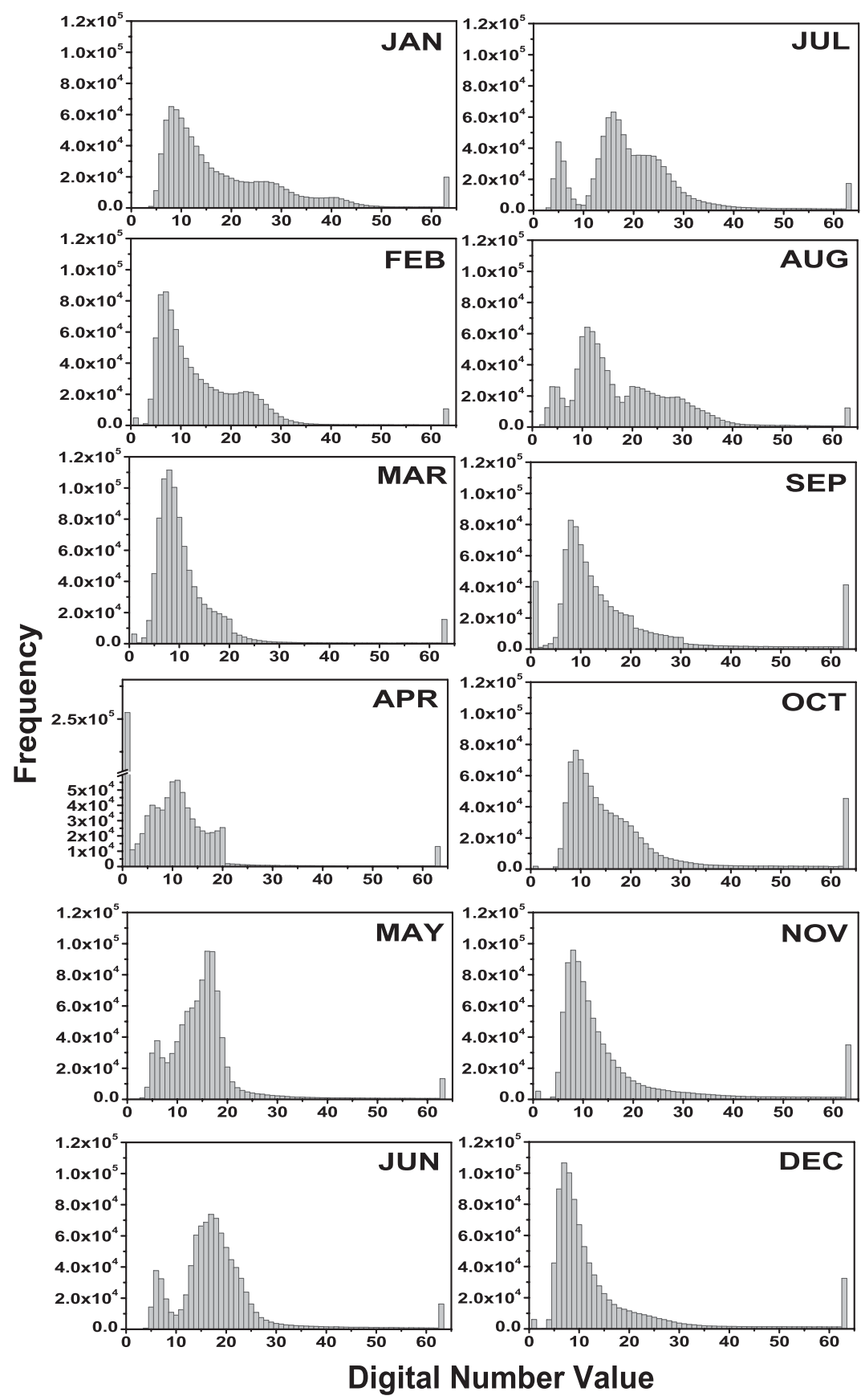

Fig. 6. Histograms of digital numbers derived from monthly composite DMSP/OLS images from 1994 to 1999
When 2 classes are divided by a threshold, $k$, and the variance, $\sigma^{2}(k)$, between 2 classes is at a maximum, then $k$ is selected as the optimal threshold. The equation for $\sigma^{2}(k)$ is:

$$
\sigma^{2}(k)=\omega_{0}\left(\mu_{0}-\mu_{T}\right)^{2}+\omega_{1}\left(\mu_{1}-\mu_{T}\right)^{2}
$$

where

$$
\begin{aligned}
& \omega_{0}=\sum_{i=1}^{k} p_{i}, \omega_{1}=\sum_{i=k+1}^{l} p_{i} \\
& \mu_{0}=\sum_{i=1}^{k} i p_{i} / \omega_{0}, \mu_{1}=\sum_{i=k+1}^{l} i p_{i} / \omega_{1}, \mu_{T}=\sum_{i=1}^{l} i p_{i} \\
& p_{i}=n_{i} / N
\end{aligned}
$$

$n_{i}$ is the number of pixels at level $i$ and $N$ is the total number of pixels; $p_{i}$ is the probability distribution of digital number value at level $i$. This method can distinguish only 2 classes from the frequency distributions; however, several distributions were confirmed by the DN frequency-distribution (Fig. 6). First we used DN values of 0 to 30 to determine a threshold. After the threshold was determined, then $30 \mathrm{DN}$ values were added to the obtained threshold and the same procedure was employed to determine the next threshold. As a result, 3 or 4 thresholds were identified (Table 1). Class 1 and 2 thresholds indicate ocean water or cloud coverage, and Class 3 and 4 thresholds bright areas arising from fishing vessel lights. Class 3 (January, April, May, from September to December) and Class 4 (all other months) threshold values were applied to extract the bright areas from the fishing vessel lights.

Image classification and signatureseparability analysis: The most widely used method for extracting surface information from remotely-sensed images is image classification, although it is usually applied to land-mapping or plant-community analysis (e.g. Thomas et al. 2002). Image classification usually employs several spectral bands such as a Landsat TM (thematic mapper) image or other remotely-

Table 1. Thresholds of digital numbers calculated from histogram in Fig. 6. -: no data

\begin{tabular}{|lcccccccccccc|}
\hline Class & Jan & Feb & Mar & Apr & May & Jun & Jul & Aug & Sep & Oct & Nov & Dec \\
\hline 1 & 16 & 15 & 12 & 20 & 13 & 10 & 10 & 7 & 15 & 16 & 14 \\
2 & 31 & 22 & 22 & 30 & 23 & 19 & 21 & 19 & 25 & 26 & 24 \\
3 & 44 & 31 & 33 & 43 & 34 & 27 & 31 & 28 & 37 & 38 & 36 & 36 \\
4 & - & 42 & 46 & - & - & 39 & 42 & 39 & - & - & - & - \\
\hline
\end{tabular}


sensed images. In this study, for fishing area formation analysis, each monthly image was considered as an individual spectral band. Monthly image data sets from 1994 to 1999 were used to create a composite image for each month using ERDAS's (earth resources data analysis system) image-interpreter of 'Imagine 8.5'. For reference purposes, we created a signature from the yearly composite image data for 9 areas of interest using ERDAS Imagine 8.5. We employed a supervised classification, using the 9 signature class means. We applied the maximum likelihood method. After this process, signature-separability analysis was applied. Swain \& Davis (1978) described 3 measures of separability: divergence, Jeffries-Matushita (J-M) distance, and transformed divergence. Mausel et al. (1990) concluded that for supervised classification of multispectral data, J-M distance yields slightly better results than other 2 separability measurements. Therefore, in this study, Jeffries-Matushita distance was applied to yearly composite-image data to assess spatial formation of the squid fishing area. The following algorithms of Erdas Imagine 8.5 calculate the J-M distances:

$$
J M_{i j}=\sqrt{2\left(1-\mathrm{e}^{-\alpha}\right)}
$$

where

$$
\alpha=\frac{1}{8}\left(\mu_{i}-\mu_{j}\right)^{T}\left(\frac{C_{i}+C_{j}}{2}\right)^{-1}\left(\mu_{i}-\mu_{j}\right)+\frac{1}{2} \ln \left\{\frac{\left|\left(C_{i}+C_{j}\right) / 2\right|}{\sqrt{\left|C_{i}\right| \times\left|C_{j}\right|}}\right\}
$$

$J M_{i j}=$ Jeffries-Matushita distances between Class $i$ and Class $j, T=$ the transpose of the matrix, $C_{i}=$ the covariance matrix of Class $i_{\text {, and }} \mu_{i}=$ the mean vector of Class i. Hence, J-M distances range between 0 and 1.414 and can be used to determine which fishing areas should be grouped according to their temporal variability. The success of a supervised image classification depends on the separability of the temporal variations for different squid fishery areas in the imagery.


Fig. 7. (a) Time series and (b) autocorrelation coefficients in the 9 areas (A-I) of interest (see Fig. 5)

\section{RESULTS}

\section{Annual variability in $\mathrm{DN}$ values extracted from DMSP/OLS nighttime visible images}

The AOIs exhibited large variability in DN in different seasons (Fig. 7a). In Areas A, B, and $\mathrm{C}$ in the northern and central part of the Sea of Japan, DN peaks occurred in wintertime, especially in November. The east coast of Korea (Area D) and the western Tsugaru Strait (Area I) showed similar summer and autumn peaks, despite the comparatively great distance between these 2 areas. In Areas $\mathrm{E}$ and $\mathrm{F}$ in the Tsushima Strait, DN varied remarkably, with decreased values in summertime. South of the Oki Islands in Area $G$, values seemed to vary randomly. Off the north-ern Noto Peninsula (Area $\mathrm{H}$ ), bright areas caused by concentrations of fishing vessels were seen only in summer, especially in May and June. These results indicate that DN varied seasonally in all areas. Fig. 7b illustrates the autocorrelation coefficient for each of the 9 areas over the preceding 24 months. The time series retained significant autocorrelation at around Months 12 and 24. This annual variability, believed to be caused by movements of the squid fishing vessels, demonstrates the need to divide the Sea of Japan into several provinces based on the seasonal variability of fishing areas, in order to archive a complete understanding of the spatial and temporal squid fishing area distribution. 


\section{Spatial distribution of Todarodes pacificus fishing area}

The yellow areas in Fig. 8 were extracted by 2-level slicing methods (see 'Materials and methods') and represent fishing-vessel lights, particularly those fishing for Todarodes pacificus. The fishing areas were mainly around the Tsushima Strait in January, extending to Ulleung Island along the east coast of Korea and the Oki Islands near the Japanese coast. February and March showed similar spatial patterns in fishing area. Their extent, however, seemed smaller than in January. In April, fishing areas spread into 2 branches at latitude $36^{\circ} \mathrm{N}$, longitude $127^{\circ} \mathrm{E}$, with 1 branch located along the east coast of Korea and the other along Japan's Honshu Island. The patterns visible in April intensified in May, especially in Korean waters. In Japanese waters, the fishing areas in May extended from the Oki Islands to Sado Island.

In June, a squid fishing area formed along the northern edge of Yamato Rise, and the northern edge of the squid fishing areas along the Japan coast had extended to the western Tsugaru Strait and to waters off southwestern Hokkaido. In July (Fig. 8), fishing areas contracted and disappeared along the Japanese coast from the Tsushima Strait to the western Tsugaru Strait, and reappeared in northern areas off the Hokkaido coast. Although the fishing areas in August generally resembled those in July, the fishing area along the Hokkaido coast disappeared in August. September saw an increase in fishing areas, especially around the Yamato Rise, the east coast of Korea and Japanese waters from Tsushima Strait to the Oki Islands. Note that September fishing areas spread continuously from Ulleung Island to the western Tsugaru Strait and across the Yamato Rise.

In October and November, fishing areas formed 2 distinct areas. One area formed around Korea's eastern coast and spread to the Yamato Rise, as in September; the other in the north above latitude $42^{\circ} \mathrm{N}$. By November, the October fishing areas around Ulleung Island and Yamato Rise formed a dense aggregation from the southern edge of the Yamato Rise to the Oki Islands. In December, the main fishing areas formed along the east coast of Korea and near the Oki Islands (Fig. 8). No fishing area was recorded farther north than about latitude $40^{\circ} \mathrm{N}$. Fishing areas along the latitude $40^{\circ} \mathrm{N}$ line stretched from Ulleung Island to off the coast of Japan.

\section{Image classification and signature-separability analysis}

Image classification identified 7 different areas of temporal variability in fishing-vessel distribution. Table 2 illustrates the results of the signature analysis. The average distance was 1.4, indicating high separability, i.e. that the 7 fishing areas were successfully identified to class. The 7 classes have distinct spatial patterns (Fig. 9) and represent different months (Fig. 10).

Class 1 (Fig. 9) was located around latitude $41^{\circ} \mathrm{N}$, extending from north Korean waters and the Hokkaido coastline to the Yamato Rise. Class 1 was also seen in the northern part of the Sea of Japan. Class 1 fishing areas appeared from August to September (Fig. 10). Class 2 (Fig. 9) was located around Ulleung Island, Cheju Island, and the coast of Hokkaido, with the largest areas near Ulleung Island. Class 2 occurred in January and continuously from May to December (Fig. 10). Taking into consideration the mean DN and the locations of the fishing area, fishing area occurred mainly from July to December. Spatial patterns of Class 3 (Fig. 9) were similar to those of Class 1; vessels were identified around latitude $40^{\circ} \mathrm{N}$, from the Korean coastline to the Yamato Rise and along the western coast of Hokkaido. However, temporal variability differed from that of Class 1, as Class 3 fishing areas were recorded from May to November (Fig. 10). Class 4 (Fig. 9) followed the Japan coast from the Oki Islands to northern Honshu, with none identified in Korean waters. Class 4 fishing areas developed from April to June, as well as in December (Fig. 10). Spatial distributions of Class 5 (Fig. 9) extended from southwest of Tsushima Island to latitude $37^{\circ} \mathrm{N}$, along the coast of Korea, to the Oki Islands along the Japanese coast. Fishing areas were recorded in all seasons (Fig. 10). Class 6 (Fig. 9) had the largest distribution of all the classes, extending between the Oki Islands and Yamato Rise and into northern parts of the Sea of Japan. This class of fishing areas appeared in November and

Table 2. Jefferies-Matushita (J-M) distance for 7 classified areas using all 12 month images

\begin{tabular}{|c|c|c|c|c|c|c|c|c|c|c|c|c|c|c|c|c|c|c|c|c|c|}
\hline \multirow{3}{*}{$\begin{array}{l}\text { Avg. } \\
\text { dist. }\end{array}$} & \multicolumn{21}{|c|}{ J-M distance (class combination) } \\
\hline & 1 & 1 & 1 & 1 & 1 & 1 & 2 & 2 & 2 & 2 & 2 & 3 & 3 & 3 & 3 & 4 & 4 & 4 & 5 & 5 & 6 \\
\hline & 2 & 3 & 4 & 5 & 6 & 7 & 3 & 4 & 5 & 6 & 7 & 4 & 5 & 6 & 7 & 5 & 6 & 7 & 6 & 7 & 7 \\
\hline 1.4 & 1.37 & 1.41 & 1.41 & 1.37 & 1.39 & 1.41 & 1.41 & 1.39 & 1.4 & 1.41 & 1.4 & 1.41 & 1.38 & 1.41 & 1.41 & 1.4 & 1.4 & 1.41 & 1.37 & 1.41 & 1.41 \\
\hline
\end{tabular}



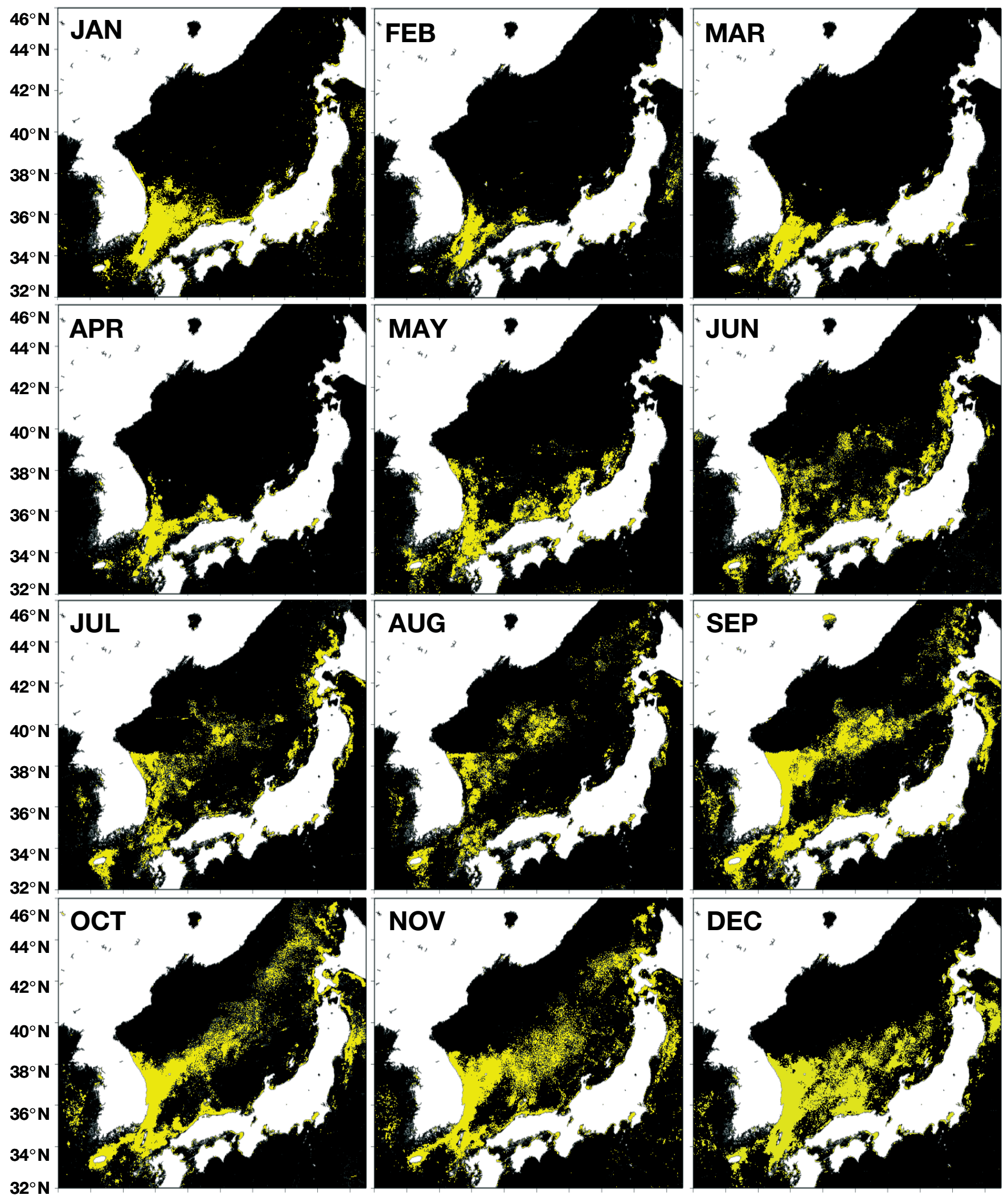

$124^{\circ} \mathrm{E} \quad 128^{\circ} \mathrm{E} \quad 132^{\circ} \mathrm{E} \quad 136^{\circ} \mathrm{E} \quad 140^{\circ} \mathrm{E} \quad 124^{\circ} \mathrm{E} \quad 128^{\circ} \mathrm{E} \quad 132^{\circ} \mathrm{E} \quad 136^{\circ} \mathrm{E} \quad 140^{\circ} \mathrm{E} \quad 124^{\circ} \mathrm{E} \quad 128^{\circ} \mathrm{E} \quad 132^{\circ} \mathrm{E} \quad 136^{\circ} \mathrm{E} \quad 140^{\circ} \mathrm{E}$

Fig. 8. DMSP/OLS nighttime monthly composite images from 1994 to 1999. Yellow area: fishing vessel lights 


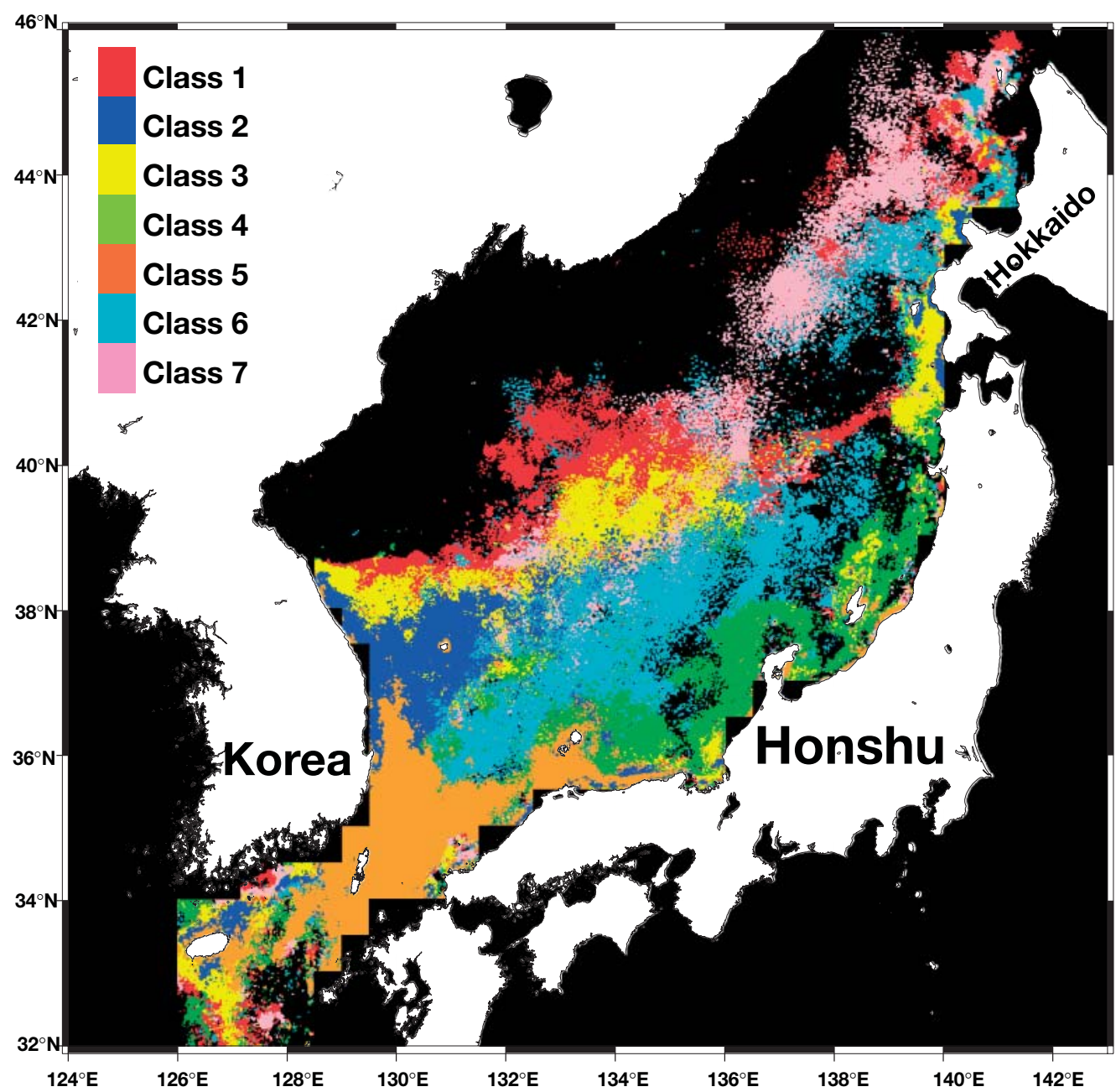

Fig. 9. Spatial distribution of 7 classified areas

December (Fig. 10). Spatial distributions of Class 7 (Fig. 9) were identified only in northern waters of the Sea of Japan. Class 7 had the shortest period of all classes, being recorded only in October (Fig. 10).

The results show distinctive spatial and temporal patterns of fishing area formation that can be detected by nighttime visible images and determined through image-classification techniques.

\section{DISCUSSION}

Most studies of squid distribution or migration have used only in situ data collected by shipboard observations or tagging experiments (e.g. Murata 1989). This paper used DMSP/OLS nighttime visible images to locate fishing vessel lights and determine the location of fishing vessels in different areas and periods. Our classification divided the Sea of Japan into 7 distinct areas of seasonal fishing that correspond to the seasons and locations of Todarodes pacificus fishing areas, as reported by Araya (1976), Hatanaka et al. (1985), and Murata (1989). Although information on fishing in Korean waters is limited, our results also agree with the annual variations in $T$. pacificus fishing area reported by Choi et al. (1997).

When considering variations in squid abundance and migration patterns, it is important to examine the spatial and temporal patterns of squid fishing area formation in the Sea of Japan. Our results show that seasonal patterns may be related to physical processes and to the annual life cycle of the squid. One of the important findings of this study is that the 7 classified areas coincide with the previously-reported oceanographic characteristics of the Sea of Japan (see Table 3 for summary).

Oceanographic associations such as fronts or sea surface temperature have been shown to influence Illex argentinus in the South Atlantic (Waluda et al. 1999, 2001a,b). Fiedler \& Bernard (1987) documented feeding aggregations associated with oceanic fronts detected by satellite imagery. Podestá et al. (1993) 


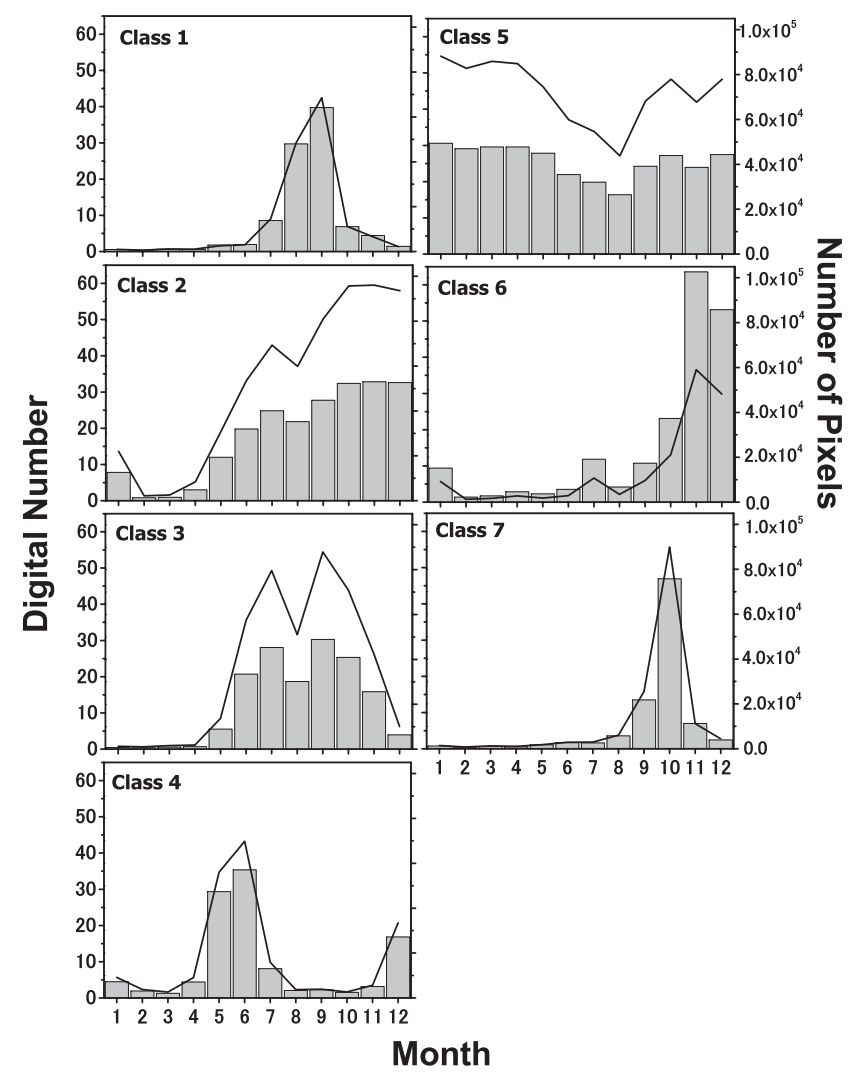

Fig. 10. Mean digital number (lines) and number of pixels (bars) for each area classified in Fig. 9

reported a close association between swordfish longline effort and oceanic features, such as shelf breaks and thermal fronts. Herron et al. (1989) found that the butterfish catch rate increased with an increase in SST gradient. These studies show that frontal features strongly influence the biological productivity of an area in terms of the presence of secondary producers, which attract higher trophic levels feeders, such as Todarodes pacificus. Class 1 and Class 3 fishing areas formed at the center of the Sea of Japan, around the Yamato Rise. Isoda (1994) pointed out that the polar front stretches across latitude $40^{\circ} \mathrm{N}$, and Classes 1 and
3 formed to the north and south area of this front, respectively.

Isoda \& Saitoh (1993) analyzed satellite SST images and hydrographic data along the east coast of Korea. Their research showed warm eddies intruding northward from spring to summer around the Ulleung Basin, and the presence of relatively stable northward currents along the eastern coast of Korea in autumn. Kim et al. (2002) reported the characteristics of the temporal variations in sea level at Ulleung Island and concluded that short-term variations in sea level are caused primarily by the movement of the warm eddies around the Island. Choi et al. (1997) noted that the squid-angling fishery started to move north in April and then south in September. Mesoscale eddies are also important in the enhancement of phytoplankton production (e.g. Saitoh et al. 1998) and the distribution of Pacific sardine larvae (Logerwell \& Smith 2001). In our results, Class 2 fishing areas were mainly distributed around Ulleung Island from June to December. If higher prey densities are associated with shelf-break fronts and eddies, the consistent presence of fronts and eddies comprises predictable feeding locations for higher trophic level feeders which take advantage of increased prey densities, and also a predictable fishing area. The dynamics of warm-water eddies probably also affect squid fishing area formations, as suggested by the fishing area distributions of Class 2 and the study of Choi et al. (1997).

In the laboratory, Bower \& Sakurai (1996) observed that Todarodes pacificus females rest on the bottom just before spawning. Similarly, bottom trawls often collect exhausted, spent females on the shelf and slope at 100 to $500 \mathrm{~m}$ depth (Hamabe \& Shimizu 1966), indicating that spawning females would concentrate at depths between 100 and $500 \mathrm{~m}$. Thus, topography may affect squid distribution. The main autumn and winter spawning grounds form around the Tsushima Strait (Murata 1989, and present Fig. 2). Kiyofuji et al. (1998) identified the inshore area of Korea's east coast as a possible spawning ground, primarily using satellite SST and topography data. Class 5 corresponds to this

Table 3. Summary of 7 classified areas and related oceanographic characteristics and ecological significance

\begin{tabular}{|lllll|}
\hline Class & Period & Geographical distribution & Oceanographic characteristics & Ecological significance \\
\hline 1 & Aug-Sep & Northern part of Yamato rise & Polar front & Spawning ground \\
2 & Jun-Dec & Around Ulleung Island & Ulleung warm eddy & Feeding area or migration route \\
3 & Jun-Nov & Southern part of Yamato rise & Polar front & Spawning ground and migration route \\
4 & May-Jun-Dec & Along Japanese coast & Tsushima Warm Current & Migration and spawning areas \\
5 & All seasons & Around Tsushima Strait & Tsushima Warm Current & Spawning ground \\
6 & Oct-Dec & Yamato Basin & Warm eddies & Migration route \\
7 & Sep-Oct & Offshore area of Hokkaido & Tsushima Warm Current & Feeding and migration areas \\
\hline
\end{tabular}


known distribution. Hence, the region indicated by Class 5 could be a fishing area for both autumn and winter spawning groups. Abundance of T. pacificus is determined by recruitment during the autumn and winter spawning periods (Hatanaka et al. 1985; Murata 1989). Fishing areas that developed only in autumn were identified in Classes 1, 3 and 7, being recorded from the central to northern areas of the Sea of Japan. In winter, fishing areas formed in more southerly areas, such as the southern areas of the Yamato Rise and coastal areas of Hokkaido. Bearing in mind the spawning season and migration patterns of T. pacificus during autumn and winter, it is reasonable to consider $T$. pacificus in these classes as mixedspawning recruits.

Fish migrations can be linked to periodic occurrences and to events such as spawning and feeding migrations (Laevastu \& Larkins 1981). Although the control of Todarodes pacificus migration is not well understood, its northward migration to the northern Sea of Japan and its southward autumn-winter migra- tion are thought to be for feeding and to search for suitable spawning grounds (Hanlon \& Messenger 1996). Currents play a dominant role in determining the pattern of migration (Healey 2000). There is a possibility that $T$. pacificus would have to utilize such flows to migrate northward, in order to save energy for foraging in the northern Sea of Japan. Thus, the oceanographic features of the TWC probably influence the spatial-temporal distribution of T. pacificus. Class 4, identified in May, June, and December along the Japanese coast from the Oki Islands to northern waters off Honshu, coincides with the evolution of warm eddies influenced by interactions with the coastal current along the Japanese coast (Isoda 1996). These areas also correspond to the location of the TWC. Class 6 developed from October to December (Fig. 10) and showed the largest distribution of all classes. However, Class 6 corresponded to relatively deep-water areas with depths greater than $500 \mathrm{~m}$. Class 6 may be an area through which squid merely pass on their way to the spawning grounds in the Tsushima Strait or along the eastern coast of Korea (which correspond to Class 5). It is of note that some fishing areas occurred at similar times but at great distances apart. For instance, Classes 1 and 3 (Figs. $9 \& 10$ ) ranged from the northern waters of the east coast of Korea to the west of Tsugaru Strait and the Yamato Rise and occurred in August and September. This indicates that squid in these regions could be at a similar phase of the life cycle, since portions of the autumn or winter spawning groups follow the TWC branches that flow off eastern Korea and the Japanese coast.

The different spatial and temporal patterns of each class suggest squid movement or migration. Our results show northern and southern migration patterns. One of the northern migration patterns was along Honshu Island to northern areas of the Sea of Japan, another ran along Korea's east coast northward through the Yamato Rise to northern areas of the Sea of Japan. The southern migration pattern was a reversal of the northern migration pattern (Fig. 11).

Another important finding is that fishing activities occurred across a wide area, and continued through- 
out the year in at least one area of the Sea of Japan. This indicates that squid resources in the Sea of Japan are very important not only as human food but also for their role in the energy and material flows in marine ecosystems. Although the trophic interrelationships between Todarodes pacificus and other species are not fully understood, the squid fishery in Japan may also impact associated species.

To estimate the impact of fishing activity on total squid stocks, it is important to take into account variations in fishing area formation by region and season. In our study, the 7 classified areas show distinctive spatial and temporal patterns in fishing areas. Examination of the distribution and abundance of squid in each of the 7 areas classified herein could assist in the management of stocks by providing additional or reduced catch to each fishing area for stock management purposes. For example, Class 5 corresponds to the spawning areas reported previously by Murata (1990). It must therefore be assumed that spent females are present in this region, and therefore fishing activities should be reduced and calculation of the total allowable catch (TAC) should take this into account for squid stocks the following year. We believe particular emphasis should also be placed on evaluating catches in each of the 7 areas, particularly during main fishing periods. This could be directly translated into specific policies for squid catch management in the Sea of Japan.

To summarize, we examined the spatial and temporal patterns of Todarodes pacificus fishing areas in the Sea of Japan using a nighttime visible data set of DMSP/OLS from 1994 to 1999. The methodology provided information on the geographical location and seasonal periodicity of $T$. pacificus fishing areas in the Sea of Japan. Our results indicate that the DMSP/OLS is capable of detecting fishing vessel lights at night in the Sea of Japan. The lights move northward from the Tsushima Strait from winter to summer before turning southward again from autumn to winter.

An important aspect of this study has been its use of image-classification to determine the temporal variability of high DN values in DMSP/OLS nighttime visible images. This approach also differs from that in land-use studies that divides spectral data into classes (Thomas et al. 2002), as well as other fishery research that uses DMSP/OLS data (Waluda et al. 2002). Although some problems with respect to mixed classes still remain, they are unlikely to have markedly affected our interpretations of the spatial and temporal fishing area formation.

Classifying remotely-sensed images provides a new way to derive detailed information on spatial and temporal dynamics of fishing vessels in the Sea of Japan. Remotely-sensing and classification methods were used successfully to locate areas that had a high poten- tial probability of forming squid fishing areas. We believe the results appropriately indicate squid locations, since powerful lights on vessel attract squid. This study has also provided quantitative evidence that variations in the spatial pattern of fishing vessel lights in the Sea of Japan can be linked to squid migration ecology. However, effective classification is difficult unless environment variables are taken into account. These environmental variables should provide details on fishing area formation to help define ecologically meaningful associations. Future research should incorporate data on environmental variables in order to better understand the ecological structures and functions of each class area. Another prerequisite for understanding the potential role of an area is an understanding of the early life stages of the squid and the relationships between squid movements and typical oceanic features.

Continual monitoring of Todarodes pacificus stocks in the Sea of Japan will be required to assess management efficiency and estimate the TAC. Targeting the entire area around Japan will not accurately determine the total catch. Fishing regions having the greatest impact on the TAC must be determined. Thus, our classification of 7 distinct areas can aid in squid catch management by providing useful information on the spatial and temporal formations of squid fishing areas. This study presents an innovative methodological approach to ocean ecological research and fisheries oceanographic research.

Acknowledgements. We would like to express out thanks to Dr. Christopher D. Elvidge, NGDC/NOAA, for providing OLS data. We are also grateful to Dr. Y. Sakurai of the Graduate School of Fisheries Sciences, Hokkaido University and to Dr. K. Cho of Tokai University Research and Information Center for providing useful comments. This work was partly supported by grants from the Research Fellowships of the Japan Society for the Promotion of Science (JSPS) for Young Scientists (H. K.), the Sasakawa Scientific Research Grant from the Japan Science Society to H. K., and Grant-in-Aid for Scientific Research (B) (2) to S. S. (No. 70250503: Fisheries Science) from the Ministry of Education, Science, Sports and Culture of Japan in 1998 and 1999.

\section{LITERATURE CITED}

Araya H (1976) Migration and fishing ground of winter subpoplation of the squid, Todarodes pacificus Steenstrup, in the Northern waters of Japan. Bull Hokkaido Reg Fish Res Lab 41:119-129

Basson M, Beddington JR, Crombie JA, Holden SJ, Purchase LV, Tingley GA (1996) Assessment and management techniques for migratory annual squid stocks: Illex argentinus fishery in the Southwest Atlantic as an example. Fish Res 28:3-27

Bower JR, Sakurai Y (1996) Laboratory observations Todarodes pacificus (Cephalopoda: Ommastrephidae) egg masses. Am Malacol Bull 13:65-71 
Cho K, Ito R, Shimoda H, Sakata T (1999) Fishing fleets lights and sea surface temperature distribution observed by DMSP/OLS sensor. Int J Remote Sens 20:3-9

Choi KO, Hwang SD, Kim JL (1997) Fishing conditions of common squid (Todarodes pacificus Steenstrup) in Korean waters I. Spatio-temporal distribution of common squid related to the changes in oceanographic conditions. J Korean Fish Soc 30:513-522 (in Korean with English abstract)

Elvidge CD, Baugh KE, Hobson VR, Kihn EA, Kroehl HW, Davis ER, Cocero D (1997a) Satellite inventory of human settlements using nocturnal radiation emissions: a contribution for the global toolchest. Glob Change Bio 3: 387-395

Elvidge CD, Baugh KE, Kihn EA, Kroehl HW, Davis ER (1997b) Mapping city lights with nighttime data from the DMSP operational linescan system. Photogram Eng Remote Sens 63:727-734

Elvidge CD, Baugh KE, Dietz JB, Bland T, Sutton PC, Kroehl HW (1999) Radiance Calibration of DMSP-OLS low light imaging data of human settlements. Remote Sens Environ 68:77-88

Fiedler PC, Bernard HJ (1987) Tuna aggregation and feeding near fronts observed in satellite imagery. Cont Shelf Res 7: $8871-8881$

Hamabe M, Shimizu T (1966) Ecological studies on the common squid, Todarades pacificus Steenstrup, in the southeastern waters of the Japan Sea. Bull Jpn Sea Reg Fish Res Lab 16:13-55 (in Japanese with English abstract)

Hanlon RT, Messenger JB (1996) Cephalopod behaviour. Cambridge University Press, Cambridge

Hatanaka H, Kawahara S, Uozumi Y (1985) Comparison of life cycles of five ommastrephid squids fished by Japan: Todarodes pacificus, Illex illecebrosus, Illex argentinus, Nototodarus sloani sloani and Nototodarus sloani gouldi. Northwest Atl Fish Organ Sci Counc Stud 9:59-68

Healey MC (2000) Pacific salmon migration in a dynamic ocean. In: Harrison PJ \& Parsons TR (eds) Fisheries oceanography: an integrative approach to fisheries ecology and management. Blackwell Science, Oxford, p 29-54

Herron PC, Leming TD, Li J (1989) Satellite-detected fronts and butterfish aggregations in the northeastern Gulf of Mexico. Cont Shelf Res 9:6569-6588

Imhoff ML, Lawrence WT, Elvidge CD, Paul T, Levine E, Privalsky MV, Brown V (1997) Using nighttime DMSP/OLS images of city lights to estimate the impact of urban land use on soil resources in the Unites States. Remote Sens Environ 59:105-117

Isobe A (1999) On the origin of the Tsushima Warm Current and its seasonality. Cont Shelf Res 19:117-133

Isobe A, Tawara S, Kaneko A, Kawano M (1994) Seasonal variability in the Tsushima Warm Current, TsushimaKorea Strait. Cont Shelf Res 14:23-35

Isoda Y (1994) Interannual SST variations to the north and south of the polar front in the Japan Sea. Mer 32:285-293

Isoda Y (1996) Interaction of warm eddy with the coastal current at the eastern boundary area in the Tsushima Current region. Cont Shelf Res 16:1149-1163

Isoda Y, Saitoh S (1993) The northward intruding eddy along the east coast of Korea. J Oceanogr 49:443-458

Kang YS, Kim JY, Kim HG, Park JH (2002) Long-term changes in zooplankton and its relationship with squid, Todarodes pacificus, catch in Japan/East Sea. Fish Oceanogr 11:337-346

Kawabe M (1982) Branching of the Tsushima Current in the Japan Sea. Part I. Data analysis. J Oceanogr Soc Jpn 38: 183-192
Kim K, Cho YK, Choi BJ, Kim YG, Beardsley RC (2002) Sea level variability at Ulleung Island in the East (Japan) Sea. J Geophys Res 107:doi:10.1029/2001JC000895

Kiyofuji H, Saitoh S, Sakurai Y (1998) A visualization of the variability of spawning ground distribution of Japanese common squid (Todarodes pacificus) using marine-GIS and satellite data sets. In: Chikatsu H, Shimizu E (eds) Proc Int Symp Real-Time Imaging and Dynamics Analysis, International Society of Photographic Remote Sensing, Commission V, Coventry, p 882-887

Kiyofuji H, Saitoh S, Sakurai Y, Hokimoto T, Yoneta K (2001) Spatial and temporal analysis of fishing fleet distribution in the southern Japan Sea in October 1996 using DMSP/ OLS visible data. In: Nishida T, Kailola PJ, Hollingworth CE (eds) Proc First Int Symp Geographical Information System (GIS) in Fishery Science, Fishery GIS Research Group, Saitama, p 178-185

Kiyofuji H, Kumagai K, Saitoh S, Arai Y, Sakai K (in press) Spatial relationship between Japanese common squid (Todarodes pacificus) fishing ground formation and fishing ports in 1998 using GS/GIS, In: Nishida T, Kailola PJ, Hollingworth CE (eds) Proc Second Int Symp Geographical Information System (GIS) in Fishery Science, Fishery GIS Research Group, Saitama

Laevastu T, Larkins HA (1981) Marine fisheries ecosystem: its quantitative evaluation and management. Fishing News Books, Farnham

Logerwell EA, Smith PE (2001) Mesoscale eddies and survival of late stage Padific sardine (Sardinops sagax) larvae. Fish Oceanogr 10:13-25

Mausel PW, Kramber WJ, Lee JK (1990) Optimum band selection for supervised classification of multispectral data. Photogram Eng Remote Sens 56:55-60

Murata M (1989) Population assessment, management and fishery forecasting for the Japanese common squid, Todarodes pacificus. In: Cabby JR (ed) Marine invertebrate fisheries: their assessment and management. John Wiley \& Sons, New York, p 613-636

Murata M (1990) Oceanic resources of squids. Mar Behav Physiol 18:19-71

Owen TW, Gallo KP, Elvidge CD, Baugh KE (1998) Using DMSP-OLS light frequency data to categorize urban environments associated with US climate observing station. Int J Remote Sens 19:3451-3456

Piatkowski U, Pierce GJ, Morais da Cunha M (2001) Impact of cephalopods in the food chain and their interaction with the environment and fisheries: an overview. Fish Res 52: $5-10$

Podestá GP, Browder JA Hoey JJ (1993) Exploring the association between swordfish catch rates and thermal fronts on U.S. longline grounds in the western North Atlantic. Cont Shelf Res 13:253-277

Rodhouse PG., Elvidge CD, Trathan PN (2001) Remote sensing of the global light-fishing fleet: an analysis of interactions with oceanography, other fisheries and predators. Adv Mar Biol 39:261-303

Saitoh S, Inagake D, Sasaoka K, Ishizaka J, Nakame Y, Saino $\mathrm{T}$ (1998) Satellite and ship observations off Kuroshio warm-core ring 93A off Sanriku, Northwestern North Pacific, in spring 1997. J Oceanogr 54:495-508

Sakurai Y, Kiyofuji H, Saitoh S, Goto T, Hiyama Y (2000) Changes in inferred spawning areas of Toderades pacificus (Cephalopoda: Ommastrephidae) due to changing environment conditions. ICES J Mar Sci 57:24-30

Swain PH, Davis SM (1978) Remote sensing: the quantitative approach. McGraw-Hill, New York

Takagi M, Shimoda H (1998) Handbook of image analysis, 
University of Tokyo Press, Tokyo (in Japanese)

Thomas V, Treitz $\mathrm{P}$, Jelinski D, Miller J, Lafleur $\mathrm{P}$, McCaughey JH (2002) Image classification of northern peatland complex using spectral and plant community data. Remote Sens Environ 84:83-99

Waluda CM, Trathan PN, Rodhouse PG. (1999) Influence of oceanographic variability on recruitment in the Illex argentinus (Cephalopoda: Ommastrephidae) fishery in the South Atlantic. Mar Ecol Prog Ser 183:159-167

Waluda CM, Rodhouse PG, Podesta GP, Trathan PN, Pierce GJ (2001a) Surface oceanography of the inferred hatching

Editorial responsibility: Kenneth Sherman (Contributing

Editor), Narrangansett, Rhode Island, USA grounds of Illex argentinus (Cephalopoda: Ommastrephidae) and influences on recruitment variability. Mar Biol 139:671-679

Waluda CM, Rodhouse PG, Trathan PN, Pierce GJ (2001b) Remotely sensed mesoscale oceanography and the distribution of Illex argentinus in the South Atlantic. Fish Oceanogr 10:207-216

Waluda CM, Trathan PN, Elvidge CD, Hobson VR, Rodhouse PG (2002) Throwing light on straddling stocks of Illex argentinus: assessing fishing intensity with satellite imagery. Can J Fish Aquat Sci 59:592-596

Submitted: June 2, 2003; Accepted: February 17, 2004 Proofs received from author(s): July 6, 2004 